\title{
Solubility of Lamotrigine, Diazepam, and Clonazepam in Ethanol + Water Mixtures at 298.15 K
}

\author{
Ali Shayanfar, ${ }^{\dagger}$ Mohammad A. A. Fakhree, ${ }^{\S}$ William E. Acree, Jr., and Abolghasem Jouyban ${ }^{*,}$ \\ Biotechnology Research Center and Faculty of Pharmacy and Drug Applied Research Center, Tabriz University (Medical \\ Sciences), Tabriz 51664, Iran, Kimia Research Institute, Tabriz, Iran, and Department of Chemistry, University of North Texas, \\ Denton, Texas 76203-5070
}

\begin{abstract}
Experimental solubilities of three antiepileptic drugs, that is, lamotrigine, diazepam, and clonazepam in ethanol + water mixtures at $298.15 \mathrm{~K}$ were reported. The solubility of drugs was increased with the addition of ethanol, reached the maximum values, and then decreased with further increase in ethanol concentrations. The Jouyban-Acree model was fitted to the data, and the solubilities were reproduced using two previously developed relationships employing a number of the solvent's and solute's parameters and the solubility data in monosolvents in which the overall mean deviations (OMDs) of the models were 6.2\%, $22.3 \%$, and $23.2 \%$.
\end{abstract}

\section{Introduction}

The solubility of drugs is essential information in drug discovery and development investigations in the pharmaceutical industry. The solubilization of drugs is very important in the preparation of liquid drug formulation stages in the pharmaceutical industry. There are many methods for solubilization of drugs including cosolvency, surface active agents, salt formation, complexation, hydrotropism, crystal engineering, preparation of soluble prodrug, and, more recently, the addition of ionic liquids. $^{1-8}$ Among these methods, the cosolvency, or the addition of a cosolvent (permissible organic solvent) to the aqueous solution to alter the aqueous solubility, is the most common and easy-to-use method. Ethanol is a common organic solvent that was used in many commercially available oral, parenteral, and soft gelatin pharmaceutical formulations for poorly soluble drugs. ${ }^{9}$ The concentration of the cosolvent in pharmaceutical preparations should be kept as low as possible because of the possible toxicity of the cosolvent and also because of the cost effect. The method that is often used to optimize the solvent composition of solvent mixtures for dissolving a desired amount of a drug in a given volume of the solution is the trial and error approach, which is time consuming and costly; moreover, in the early stages of drug discovery processes, the scarcity of the available amount of drug is another limiting factor. To address this issue, a number of mathematical models have been presented for predicting the solubility of drugs in water-cosolvent mixtures. These models and their advantages and limitations were recently reviewed. ${ }^{10}$

Of the numerous models developed in recent years, the Jouyban-Acree model is perhaps one of the more versatile models. The model provides very accurate mathematical descriptions for how the solute solubility varies with both temperature and solvent composition. The model for represent-

\footnotetext{
* To whom correspondence should be addressed. E-mail: ajouyban@ hotmail.com; Fax: +98 4113363231.

Biotechnology Research Center, Tabriz University.

$\doteqdot$ Faculty of Pharmacy and Drug Applied Research Center, Tabriz University.

$\S$ Kimia Research Institute.

"University of North Texas.
}

ing the solubility of a solute in binary mixture at various temperature is

$$
\log C_{m, T}^{\mathrm{Sat}}=x_{1} \log C_{1, T}^{\mathrm{Sat}}+x_{2} \log C_{2, T}^{\mathrm{Sat}}+\left[\frac{x_{1} x_{2}}{T} \sum_{i=0}^{2} J_{i}\left(x_{1}-x_{2}\right)^{i}\right]
$$

where $C_{m, T}^{\mathrm{Sat}}$ is the solute $\left(\mathrm{mol} \cdot \mathrm{L}^{-1}\right)$ solubility in the solvent mixtures at temperature $T, x_{1}$ and $x_{2}$ are the fractions of the solvents 1 (ethanol) and 2 (water) in the absence of the solute, $C_{1, T}^{\mathrm{Sat}}$ and $C_{2, T}^{\mathrm{Sat}}$ denote the $\mathrm{mol} \cdot \mathrm{L}^{-1}$ solubility of the solute in the neat solvents 1 and 2 , respectively, and $J_{i}$ are the constants of the model computed by regression analysis. ${ }^{10}$ The existence of these model constants that require a number of solubility data in water-cosolvent mixtures for the training process is a limitation for the model when the solubility predictions are the goal of the computations in early drug discovery studies. This limitation could be resolved using a trained version of the model for a given water-cosolvent mixture ${ }^{11}$ as well as a recently developed quantitative structure-property relationship (QSPR) model ${ }^{12}$ to predict the numerical values of the model constants. The trained version of the Jouyban-Acree model for the prediction of drug solubility in ethanol + water mixtures at $298.15 \mathrm{~K}_{\text {was }}{ }^{11}$

$$
\begin{aligned}
\log C_{m, T}^{\mathrm{Sat}}=x_{1} & \log C_{1, T}^{\mathrm{Sat}}+x_{2} \log C_{2, T}^{\mathrm{Sat}}+\frac{724.21 x_{1} x_{2}}{298.15}+ \\
& \frac{458.17 x_{1} x_{2}\left(x_{1}-x_{2}\right)}{298.15}+\frac{194.21 x_{1} x_{2}\left(x_{1}-x_{2}\right)^{2}}{298.15}
\end{aligned}
$$

The reported QSPR models using Abraham solvation parameters were $^{12}$

$$
\begin{aligned}
& J_{0}= 2113.119-1093.783\left(c_{1}-c_{2}\right)^{2}+ \\
& 3380.661 E\left(e_{1}-e_{2}\right)^{2}-13.865 S\left(s_{1}-s_{2}\right)^{2}- \\
& 4.921 A\left(a_{1}-a_{2}\right)^{2}-5.659 B\left(b_{1}-b_{2}\right)^{2}+15.250 V\left(v_{1}-v_{2}\right)^{2}
\end{aligned}
$$




$$
\begin{aligned}
& J_{1}=-2001.561+1142.780\left(c_{1}-c_{2}\right)^{2}- \\
& 2735.160 E\left(e_{1}-e_{2}\right)^{2}-38.541 S\left(s_{1}-s_{2}\right)^{2}+ \\
& 13.176 A\left(a_{1}-a_{2}\right)^{2}+0.811 B\left(b_{1}-b_{2}\right)^{2}+38.508 V\left(v_{1}-v_{2}\right)^{2}
\end{aligned}
$$

$$
\begin{aligned}
& J_{2}=1474.963-1507.479\left(c_{1}-c_{2}\right)^{2}+ \\
& \quad 4421.302 E\left(e_{1}-e_{2}\right)^{2}+17.981 S\left(s_{1}-s_{2}\right)^{2}- \\
& 21.196 A\left(a_{1}-a_{2}\right)^{2}+6.595 B\left(b_{1}-b_{2}\right)^{2}-13.386 V\left(v_{1}-v_{2}\right)^{2}
\end{aligned}
$$

where $c, e, s, a, b$, and $v$ are the solvent coefficients, subscripts 1 and 2 denote the cosolvent and water, respectively, $E$ is the excess molar refraction, $S$ is the dipolarity/polarizability of the solute, $A$ denotes the solute's hydrogen-bond acidity, $B$ stands for the solute's hydrogen-bond basicity, and $V$ is the McGowan volume of the solute in units of $0.01\left(\mathrm{~cm}^{3} \cdot \mathrm{mol}^{-1}\right)$. The numerical values of Abraham solute parameters of the drugs and the Abraham solvent coefficients employed in this work are listed in Tables 1 and 2, respectively.

In this work, the experimental solubility of lamotrigine (LTG), diazepam (DZP), and clonazepam (CZP) in ethanol + water mixtures at $298.15 \mathrm{~K}$ was reported. In addition, the fitness of the data to the Jouyban-Acree model and the prediction capability of the above-mentioned models for predicting the solubility of drugs in ethanol + water mixtures were investigated.

\section{Experimental Methods}

LTG was purchased from Arastoo pharmaceutical (Iran) and DZP and CZP were gifts from Sobhan pharmaceutical (Iran). The purity of the drugs was checked by determining their melting points and comparing the measured solubilities in monosolvents with the corresponding data from the literature. Ethanol (99.9 \%) was purchased from Merck (Germany), methanol (99.8\%) was obtained from Calendon (Canada), and double-distilled water was used for the preparation of the solutions.

Apparatus and Procedures. We prepared the binary solvent mixtures by mixing the appropriate volumes of the solvents with the accuracy of 0.10 volume fraction. The solubility of LTG, DZP, and CZP in ethanol + water mixtures was determined by equilibrating an excess amount of the solid at $298.15 \mathrm{~K}$ using a shaker (Behdad, Tehran, Iran) placed in an incubator equipped with a temperature-controlling system with $\pm 0.2 \mathrm{~K}$. After a sufficient length of time ( $>48 \mathrm{~h}$ ), the saturated solutions were filtered using hydrophilic Durapore filters $(0.45 \mu \mathrm{m}$, Millipore, Ireland) and were then diluted by water for LTG and by methanol for DZP and CZP and assayed at 309, 229, and 309 $\mathrm{nm}$, respectively, using a UV-vis spectrophotometer (Beckman DU-650, Fullerton). The preliminary investigations showed that

Table 1. Abraham Solute Parameters of the Drugs Taken from the Literature ${ }^{17,18}$

\begin{tabular}{|c|c|c|}
\hline & $\varepsilon$ & $C$ \\
\hline drug & $\mathrm{L} \cdot \mathrm{mol}^{-1} \cdot \mathrm{cm}^{-1}$ & $\mathrm{~mol} \cdot \mathrm{L}^{-1}$ \\
\hline LTG & 6681 to 6904 & $3.59 \cdot 10^{-5}$ to $1.80 \cdot 10^{-4}$ \\
\hline DZP & 45217 to 77215 & $3.48 \cdot 10^{-6}$ to $2.79 \cdot 10^{-5}$ \\
\hline $\mathrm{CZP}$ & 11297 to 12050 & $1.66 \cdot 10^{-5}$ to $1.33 \cdot 10^{-4}$ \\
\hline
\end{tabular}

\begin{tabular}{cccccc}
\hline drug & $E$ & $S$ & $A$ & $B$ & $V$ \\
\hline $\mathrm{LTG}^{a}$ & 2.79 & 2.81 & 0.50 & 1.09 & 1.65 \\
$\mathrm{DZP}^{a}$ & 2.38 & 2.11 & 0.00 & 1.15 & 2.07 \\
$\mathrm{CZP}^{b}$ & 2.46 & 1.75 & 0.33 & 1.50 & 3.02
\end{tabular}

${ }^{a}$ From ref $17 .{ }^{b}$ From ref 18.

Table 2. Abraham Solvent Coefficients Employed in This Work ${ }^{16}$

\begin{tabular}{lrrrrrr}
\hline solvent & \multicolumn{1}{c}{$c$} & $e$ & \multicolumn{1}{c}{$s$} & $a$ & \multicolumn{1}{c}{$b$} & \multicolumn{1}{c}{$v$} \\
\hline ethanol & 0.208 & 0.409 & -0.959 & 0.186 & -3.645 & 3.928 \\
water & -0.994 & 0.577 & 2.549 & 3.813 & 4.841 & -0.869
\end{tabular}

Table 3. Details of Calibration Curves

\begin{tabular}{|c|c|c|c|c|c|}
\hline$x_{1}$ & $\rho$ & \multicolumn{4}{|c|}{$C\left(\mathrm{~mol} \cdot \mathrm{L}^{-1}\right)$} \\
\hline $\begin{array}{c}\text { volume } \\
\text { fraction } \\
\text { of ethanol }\end{array}$ & $\mathrm{g} \cdot \mathrm{cm}^{-3}$ & experimental & method I & method II & method III \\
\hline \multicolumn{6}{|c|}{ LTG } \\
\hline 0.00 & 1.000 & 0.00073 & 0.00073 & 0.00073 & 0.00073 \\
\hline 0.10 & 0.988 & 0.00187 & 0.00140 & 0.00135 & 0.00164 \\
\hline 0.20 & 0.977 & 0.00231 & 0.00266 & 0.00245 & 0.00291 \\
\hline 0.30 & 0.965 & 0.00439 & 0.00509 & 0.00439 & 0.00437 \\
\hline 0.40 & 0.948 & 0.00969 & 0.00980 & 0.00770 & 0.00583 \\
\hline 0.50 & 0.931 & 0.02032 & 0.01833 & 0.01292 & 0.00721 \\
\hline 0.60 & 0.910 & 0.03562 & 0.03140 & 0.01993 & 0.00852 \\
\hline 0.70 & 0.885 & 0.04242 & 0.04528 & 0.02687 & 0.00983 \\
\hline 0.80 & 0.862 & 0.04386 & 0.04919 & 0.02959 & 0.01121 \\
\hline 0.90 & 0.831 & 0.03762 & 0.03510 & 0.02457 & 0.01264 \\
\hline 1.00 & 0.790 & 0.01398 & 0.01398 & 0.01398 & 0.01398 \\
\hline \multicolumn{6}{|c|}{ DZP } \\
\hline 0.00 & 1.002 & 0.00015 & 0.00015 & 0.00015 & 0.00015 \\
\hline 0.10 & 0.990 & 0.00039 & 0.00033 & 0.00040 & 0.00037 \\
\hline 0.20 & 0.981 & 0.00074 & 0.00082 & 0.00102 & 0.00093 \\
\hline 0.30 & 0.963 & 0.00199 & 0.00222 & 0.00257 & 0.00235 \\
\hline 0.40 & 0.950 & 0.00666 & 0.00615 & 0.00637 & 0.00579 \\
\hline 0.50 & 0.931 & 0.01673 & 0.01623 & 0.01509 & 0.01327 \\
\hline 0.60 & 0.915 & 0.03925 & 0.03811 & 0.03287 & 0.02734 \\
\hline 0.70 & 0.887 & 0.07486 & 0.07443 & 0.06255 & 0.04904 \\
\hline 0.80 & 0.867 & 0.10071 & 0.11281 & 0.09729 & 0.07424 \\
\hline 0.90 & 0.840 & 0.13473 & 0.12377 & 0.11404 & 0.09222 \\
\hline 1.00 & 0.808 & 0.09158 & 0.09158 & 0.09158 & 0.09158 \\
\hline \multicolumn{6}{|c|}{ CZP } \\
\hline 0.00 & 1.004 & 0.00010 & 0.00010 & 0.00010 & 0.00010 \\
\hline 0.10 & 0.988 & 0.00013 & 0.00013 & 0.00022 & 0.00016 \\
\hline 0.20 & 0.977 & 0.00025 & 0.00026 & 0.00049 & 0.00033 \\
\hline 0.30 & 0.965 & 0.00063 & 0.00066 & 0.00110 & 0.00074 \\
\hline 0.40 & 0.948 & 0.00190 & 0.00176 & 0.00241 & 0.00170 \\
\hline 0.50 & 0.937 & 0.00452 & 0.00430 & 0.00502 & 0.00377 \\
\hline 0.60 & 0.910 & 0.00836 & 0.00877 & 0.00964 & 0.00763 \\
\hline 0.70 & 0.883 & 0.01336 & 0.01415 & 0.01617 & 0.01325 \\
\hline 0.80 & 0.862 & 0.01788 & 0.01787 & 0.02216 & 0.01868 \\
\hline 0.90 & 0.825 & 0.01957 & 0.01824 & 0.02288 & 0.02031 \\
\hline 1.00 & 0.794 & 0.01619 & 0.01619 & 0.01619 & 0.01619 \\
\hline
\end{tabular}

Table 4. Experimental Solubilities of LTG, DZP, CZP in Ethanol + Water Mixtures at 298.15 K, Density $(\rho)$ of the Saturated Solutions, and the Computed Solubilities Using Equation 1 and Various Numerical Analyses

Table 5. Numerical Values of the Mean Deviation (MD) for the Predicted Solubilities of LTG, DZP, CZP in Ethanol + Water Mixtures Using Various Numerical Analyses and Their Overall Values

\begin{tabular}{lccc}
\hline \multicolumn{1}{c}{ drug } & method I & method II & method III \\
\hline LTG & 8.4 & 21.7 & 39.7 \\
DZP & 6.6 & 12.2 & 18.8 \\
CZP & 3.6 & 32.9 & 11.2 \\
overall MD \% & 6.2 & 22.3 & 23.2
\end{tabular}

the filter did not absorb the solutes through the filtration process. Concentrations of the diluted solutions were determined from the calibration curves. Details of calibration curves are shown in Table 3. Each experimental data point was an average of at least three repeated experiments with the measured $\mathrm{mol} \cdot \mathrm{L}^{-1}$ solubilities being reproducible within $\pm 3.5 \%$. The calculated standard deviation ranged from $\sigma_{n-1}=0.0000013$ to 0.0046685 . The densities of the saturated solutions were determined using a $5 \mathrm{~mL}$ pycnometer.

Computational Methods. In the numerical analysis of method I, eq 1 was fitted to the experimental solubility data of drugs, 
and the back-calculated solubilities were used to calculate the accuracy of the fitness. In method II, the solubilities of three drugs were predicted using eq 2 by employing the experimental solubility of drugs in neat ethanol and water. In method III, the model constants of the Jouyban-Acree model were predicted using eqs 3,4 , and 5 , and the predicted $J_{0}$ to $J_{2}$ values were used in eq 1 to predict the solubility of drugs. The mean deviation (MD) was used to check the accuracy of the prediction methods and is calculated using

$$
\mathrm{MD}=\frac{\sum\left\{\frac{\left|\left(C_{m}^{\mathrm{Sat}}\right)_{\mathrm{pred}}-\left(C_{m}^{\mathrm{Sat}}\right)\right|}{\left(C_{m}^{\mathrm{Sat}}\right)}\right\}}{N}
$$

where $N$ is the number of data points in each set.

\section{Results and Discussion}

Table 4 lists the experimental solubilities of LTG, DZP, CZP in ethanol + water mixtures at $298.15 \mathrm{~K}$, the computed solubilities of these drugs employing eq 1 using methods I, II, and III, and the density of the saturated solutions. There were good agreements between the reported solubilities of LTG in water $^{13}\left(0.00066 \mathrm{~mol} \cdot \mathrm{L}^{-1}\right.$ at $\left.298.15 \mathrm{~K}\right)$, DZP in water ${ }^{14}$ $\left(0.00015 \mathrm{~mol} \cdot \mathrm{L}^{-1}\right.$ at $(295.15$ to 297.15$\left.) \mathrm{K}\right)$, and $\mathrm{CZP}$ in ethanol ${ }^{15}\left(0.0165 \mathrm{~mol} \cdot \mathrm{L}^{-1}\right.$ at $\left.298.15 \mathrm{~K}\right)$ from the literature and the measured solubilities of LTG in water $\left(0.00073 \mathrm{~mol} \cdot \mathrm{L}^{-1}\right.$ at $298.15 \mathrm{~K})$, DZP in water $\left(0.00015 \mathrm{~mol} \cdot \mathrm{L}^{-1}\right.$ at $\left.298.15 \mathrm{~K}\right)$, and $\mathrm{CZP}$ in ethanol $\left(0.016192 \mathrm{~mol} \cdot \mathrm{L}^{-1}\right.$ at $\left.298.15 \mathrm{~K}\right)$ in this work. The solubilities of these drugs increased with the addition of ethanol, reached the maximum values, and then decreased with the further increase of ethanol concentrations. The solubilities of these drugs were predicted using numerical methods I, II, and III. The predicted solubilities were compared with the corresponding experimental data, and the MD values were computed and are listed in Table 5. In general, the overall MDs observed in these predictions show that the developed models are robust and could be used for prediction purposes with the prediction error of less than $24 \%$.

\section{Acknowledgment}

We thank Sobhan and Arastoo pharmaceutical companies for supplying the drug powders.

\section{Literature Cited}

(1) Dong, Y.; Ng, W. K.; Surana, U.; Tan, R. B. H. Solubilization and Preformulation of Poorly Water Soluble and Hydrolysis Susceptible
$N$-Epoxymethyl-1,8-Naphthalimide (ENA) Compound. Int. J. Pharm. 2008, 356, 130-136.

(2) Kawakami, K.; Oda, N.; Miyoshi, K.; Funaki, T.; Ida, Y. Solubilization Behavior of a Poorly Soluble Drug under Combined Use of Surfactants and Cosolvents. Eur. J. Pharm. Sci. 2006, 28, 7-14.

(3) Serajuddin, A. T. M. Salt Formation to Improve Drug Solubility. $\underline{A d v}$. Drug Deliverv Rev. 2007, 59, 603-616.

(4) Sanghvi, R.; Evans, D.; Yalkowsky, S. H. Stacking Complexation by Nicotinamide: A Useful Way of Enhancing Drug Solubility. $\underline{\text { Int }}$. J. Pharm. 2007, 336, 35-41.

(5) Jain, A. K. Solubilization of Indomethacin Using Hydrotropes for Aqueous Injection. Eur. J. Pharm. Biopharm. 2008, 68, 701-714.

(6) Blagden, N.; de Matas, M.; Gavan, P. T.; York, P. Crystal Engineering of Active Pharmaceutical Ingredients to Improve Solubility and Dissolution Rates. Adv. Drug Deliverv Rev. 2007, 59, 617-630.

(7) Stella, V. J.; Nti-Addae, K. W. Prodrug Strategies to Overcome Poor Water Solubility. Adv. Drug Deliverv Rev. 2007, 59, 677-694.

(8) Mizuuchi, H.; Jaitely, V.; Murdan, S.; Florence, A. T. Room Temperature Ionic Liquids and Their Mixtures: Potential Pharmaceutical Solvents. Eur. J. Pharm. Sci. 2008, 33, 326-331.

(9) Strickley, R. G. Solubilizing Excipients in Oral and Injectable Formulations. Pharm. Res. 2004, 21, 201-230.

(10) Jouyban, A. Review of the Cosolvency Models for Predicting Solubility of Drugs in Water-Cosolvent Mixtures. J. Pharm. Pharm. Sci. 2008, $11,32-58$.

(11) Jouyban, A.; Acree, W. E., Jr. In Silico Prediction of Drug Solubility in Water-Ethanol Mixtures Using Jouyban-Acree Model. J. Pharm. Pharm. Sci. 2008, 9, 262-269.

(12) Jouyban, A.; Soltanpour, S.; Soltani, S.; Chan, H. K.; Acree, W. E., Jr. Solubility Prediction of Drugs in Water-Cosolvent Mixtures Using Abraham Solvation Parameters. J. Pharm. Pharm. Sci. 2007, 10, 294308.

(13) Clarke's Analysis of Drugs and Poisons: In Pharmaceuticals, Body Fluids, and Postmortem Material, 3rd ed.; Moffat, A. C., Osselton, M. D., Widdop, B., Galichet, L. Y., Eds.; Pharmaceutical Press: London, 2004.

(14) Loftsson, T.; Hreinsdoíttir, D. Determination of Aqueous Solubility by Heating and Equilibration: A Technical Note. AAPS PharmSciTech 2006, 7, e1-e4.

(15) Hammad, M. A.; Muller, B. W. Solubility and Stability of Clonazepam in Mixed Micelles. Int. J. Pharm. 1998, 169, 55-64.

(16) Stovall, D. M., Jr.; Abraham, M. H. Solubility of 9-Fluorenone, Thianthrene and Xanthene in Organic Solvents. Fluid Phase Equilib. 2005, 232, 113-121.

(17) Zhao, Y. H.; Le, J.; Abraham, M. H.; Hersey, A.; Eddershaw, P. J.; Luscombe, C. N.; Boutina, D.; Beck, G.; Sherborne, B.; Cooper, I.; Platts, J. A. Evaluation of Human Intestinal Absorption Data and Subsequent Derivation of a Quantitative Structure-Activity Relationship (QSAR) with the Abraham Descriptors. J. Pharm. Sci. 2001, 90, 749-784.

(18) ADME Boxes, version 4.0; Pharma Algorithms: Toronto, 2008.

Received for review October 21, 2008. Accepted November 24, 2008. We thank the Drug Applied Research Center for the financial support under grant no. 87-45.

JE8007827 